\title{
Perceptions of National Service Personnel and Youth Unemployment: Could Entrepreneurship Education and Curricula Rationalization be the Solution?
}

\author{
Ato Essuman \\ Institute of Education and Entrepreneurship, Methodist University College Ghana \\ P. O. Box DC 940, Dansoman, Accra, Ghana \\ Kwame Nyamekye \\ Faculty of Business Administration, Methodist University College Ghana \\ P. O. Box DC 940, Dansoman, Accra, Ghana
}

\begin{abstract}
Youth unemployment has been a global challenge for several decades bedeviling several nations whether developed, developing or undeveloped. In Ghana graduate unemployment has been a major socio-economic challenge facing the country. About 300,000 young graduates enter the labour market every year with less than $6,000(3 \%)$ getting formal employment. It is also believed that only two out of ten graduates who complete national service ${ }^{1}$ every year get employed in the formal sector. Whilst these statistics may be very alarming, many young graduates still hold the notion that it is the responsibility of the state to provide for their economic needs and expect the government to employ them. Using mixed methods of survey and interviews, data were collected from national service personnel who participated in a training workshop on entrepreneurship. Findings reveal that there is lack of knowledge of the needed skills the job market requires and a wide disparity between what graduates are exposed to during their undergraduate training and the demands of the labour market. This paper argues that there is the need to introduce courses/programmes that would reduce the incongruence between the expectations of industry and what tertiary institutions offer, and that entrepreneurship education should be mainstreamed into the entire educational structure to heighten the creativity spirit in students. The paper concludes that without governmental and private sector support to training institutions as well as collaboration between key stakeholders in ensuring relevance and the required linkages between training providers and users, solving the unemployment challenge in the medium to long term may be far-fetched.
\end{abstract}

Keywords: entrepreneurship, education, youth, graduate unemployment

DOI: $10.7176 / \mathrm{JEP} / 10-30-07$

Publication date:October $31^{\text {st }} 2019$

\section{INTRODUCTION}

There is renewed commitment in recent years by governments in both developed and developing countries to address youth unemployment as a means to intensifying the fight against extreme poverty, achieving the SDGs, and more importantly, addressing issues of equity. This has led to an increasing demand for relevant information on how labour market operates, especially in the context of addressing youth unemployment challenges. In particular, in the last three decades, many African governments have embarked on reforms to transform education so that it can contribute to the development of skills for employment (Akyeampong 2014;AEO, 2014). Nation states have introduced technical and vocational education subjects as part of an essential skills development agenda to enhance the chances of young people finding paid work or getting into self-employment after completing their secondary education (Akyeampong, 2014). However, the experience of many African countries has not been positive. Reforms to vocationalise the secondary education curriculum in which, for example, life skills were associated with certain types of skills for employability did not produce the desired results, partly because of the ill-adapted nature of technical and vocational subjects and weak links with the labour market (Lauglo and Maclean 2005; World Bank 2005; Adams 2007).

Whilst many reasons have been assigned to the causes of unemployment, including structural factors that have shaped the world of work; such as an aging population, shifts in the skills sought by employers, it is an undeniable fact that there have also been shifts from literacy, numeracy and content mastery to include soft skills like learning skills, life skills, communication, curiosity, resilience and problem-solving abilities, among others. In Ghana about 300,000 young graduates enter the labour market every year with less than 6,000 (3\%) getting formal employment. It is also believed that only two out of ten graduates who complete national service ${ }^{2}$ every

\footnotetext{
${ }^{1}$ National Service - Ghanaian students who graduate from accredited tertiary institutions are required under law to do a one-year national service to the country.

${ }^{2}$ National Service - Ghanaian students who graduate from accredited tertiary institutions are required under law to do a one-year national service to the country.
} 
year get employed in the formal sector Amankrah and Burggraaff (2012). The National Service Scheme deployed about 100,000 service personnel across the country in the 2016/2017 Service Year. The question is, how many of these could be employed by government institutions or the private and public sector after their national service?

If indeed entrepreneurship creates jobs, drives economic growth, and fosters innovation, then country states, particularly Ghana should be giving it much more attention than it has been given now. Its significance continues to be touted by governments, academia and the private sector; yet, little has been done to actualize its momentous roll out. A key reason being suggested is that the inherited colonial educational system which focused on the development of clerical and literacy skills deemed necessary for colonial administration and for making good employees, rather than entrepreneurs out of locals, has not gone through the needed transformation required, despite the many educational reforms. That legacy continues and although most universities in Ghana have begun to offer entrepreneurship courses in recent years, entrepreneurship is taught like any other course. Tertiary education providers, as will be pointed out later in this paper, have a major role to play in redeeming the missed opportunities at the second cycle level and create the requisite environment and justification for entrepreneurship education and training to beef up the deficit and develop entrepreneurial skills sufficient to enhance the transition between tertiary education and the world of work or new venture creation.

The objective of this paper therefore, was to highlight the aspirations and experiences of national service personnel, factors that influenced their choices of programmes at the university, how the programmes they were offered had empowered them for life after their education, what role could tertiary institutions play in addressing the graduate unemployment challenge and how may this role be played? The study also sought to find out in what ways labour market demands should influence programmes being offered at tertiary institutions.

\section{LITERATURE REVIEW}

Education systems in most African countries still place a strong emphasis on knowledge and competencies for higher academic education, despite the fact that most school-leavers do not enter tertiary education. Worse still, as many young people fail to even access secondary education, with a gross enrolment ratio estimated at 35 per cent (AEO 2014), reforms to improve skills development are unlikely to benefit the majority who end up in the labour market before accessing or even completing secondary education (Akyeampong, 2014). In Ghana, for example, at least 65 per cent of lower secondary students do not make it to upper secondary education, with most of them disappearing into the informal economy (ibid). Among those who complete upper secondary education, about 60 per cent enter the labour market or seek some form of skills training (MoESS 2010). So the fact is most Ghanaian youth entering the labour market either lack basic skills because they did not complete primary or lower secondary school, or have completed upper secondary i.e. senior high school.

In emerging economies around the world, interest in entrepreneurship is currently higher than ever amid burgeoning youth populations and a desire to move up value chains. Research supports the general observation that entrepreneurship can be a crucial generator of jobs (Acs and Armington, 2004; Teixeira and Forte, 2009). Entrepreneurship is also considered as a key solution to the ever-growing problem of unemployment among graduates in many countries (Gird \& Bagraim, 2008). Since entrepreneurship is believed to be a solution to the graduate unemployment problem, ways must be found to create new entrepreneurs right after or even before they graduate. In other words, efforts should be made to produce more graduate entrepreneurs. However, in order to do that, higher education in general and entrepreneurship education in particular, may help to promote entrepreneurial activity among students (Nabi and Linan, 2011). Research seems to suggest that "individuals attending entrepreneurship courses have a higher tendency to start their own businesses at some point in their career than those attending other courses" (Jaafar and Abdul Aziz, 2008).

\section{Unemployment - A Global Phenomenon}

The ILO has predicted that global unemployment will reach 204 million in 2018 as the pace of labour force growth outstrips job creation (WESO, 2017). The ILO reports cite Latin America and sub-Saharan Africa as the two regions likely to face greater unemployment challenges since they are both are confronted with strong growth in numbers of individuals entering the working age (ibid). There are inequalities in opportunities, social discontent and wide disparities across a number of demographic groups, particularly, gender disparities in labour market opportunities, which cut across and persist in a number of areas. For instance, in Northern Africa, women in the labour force in 2017 were twice as likely as men to be unemployed (ibid.). The gap was starker for women in the Arab States, who were more than twice as likely to be unemployed as men. The gender gaps in the labour market also extend to differences in remuneration. The ILO Global Wage Report 2016/17 highlighted the gap in hourly wages, which reaches as high as 40 per cent (e.g. in Azerbaijan and Benin), continues to persist despite improvements in equal pay legislation in a number of countries (ILO, GWR, 2016/2017).

The global population is ageing and as the global population ages, young workers would be needed to support more elderly people (GETY, 2017). In 2015, youth aged 15-24 constituted 16.2 per cent of the total 
population, while adults aged 65 or older constituted 8.3 per cent. It is projected that by 2030 , the share of youth will fall slightly, to 15.2 per cent, while the share of people aged 65 or older rise to almost 12 per cent. By 2050 , it is projected that the older population will outnumber young persons (ibid.). This implies that the active workforce must sustain the pension and health-care schemes for a growing number of retired workers. Tables 1 and 2 give unemployment rates globally as they relate to developed countries emerging, and developing countries as well as unemployment rates per elected regions and countries for the periods 2015/2016-2018.

Table 1. Unemployment, vulnerable employment and working poverty trends and projections, 2016-18

Unemployment (millions)

\begin{tabular}{|l|c|c|c|c|c|c|}
\hline & $\mathbf{2 0 1 6}$ & $\mathbf{2 0 1 7}$ & $\mathbf{2 0 1 8}$ & $\mathbf{2 0 1 6}$ & $\mathbf{2 0 1 7}$ & $\mathbf{2 0 1 8}$ \\
\hline WORLD & 197.7 & & & 5.7 & 5.8 & 5.8 \\
\hline Developed countries & 38.6 & 37.9 & 38.0 & 6.3 & 6.2 & 6.2 \\
\hline Emerging countries & 143.4 & 147.0 & 149.2 & 5.6 & 5.7 & 5.7 \\
\hline Developing countries & 15.7 & 16.1 & 16.6 & 5.6 & 5.5 & 5.5 \\
\hline
\end{tabular}

Source: ILO, 2017

Table 2: Unemployment rates per region

\begin{tabular}{|c|c|c|c|c|}
\hline $\begin{array}{l}\text { WORLD/(Global } \\
\text { Rates) }\end{array}$ & $\begin{array}{c}2015 \\
5.9\end{array}$ & $\begin{array}{c}2016 \\
5.7\end{array}$ & $\begin{array}{c}2017 \\
5.8\end{array}$ & $\begin{array}{c}2018 \\
5.8\end{array}$ \\
\hline $\begin{array}{cc}\text { Latin } & \text { America } \\
\bullet & \text { Brazil } \\
\bullet & \text { Mexico } \\
\end{array}$ & $\begin{array}{l}7.1 \\
4.8\end{array}$ & $\begin{array}{c}11.5 \\
4.0 \\
\end{array}$ & $\begin{array}{c}12.4 \\
4.0\end{array}$ & $\begin{array}{c}12.4 \\
4.2 \\
\end{array}$ \\
\hline $\begin{array}{c}\text { Northern America } \\
\text { - } \quad \text { Canada } \\
\bullet \quad \text { USA } \\
\end{array}$ & $\begin{array}{l}5.7 \\
5.0 \\
\end{array}$ & $\begin{array}{l}7.1 \\
4.9 \\
\end{array}$ & $\begin{array}{l}7.1 \\
4.1 \\
\end{array}$ & $\begin{array}{l}7.1 \\
4.4\end{array}$ \\
\hline $\begin{array}{cl}\text { Sub-Saharan Africa } \\
\text { - } & \text { South Africa } \\
\text { - } & \text { Nigeria } \\
\text { - } & \text { Ghana }\end{array}$ & $\begin{array}{l}25.0 \\
10.4 \\
11.9\end{array}$ & $\begin{array}{c}25.9 \\
13.9 \\
5.8\end{array}$ & $\begin{array}{c}26.0 \\
18.8 \\
5.8\end{array}$ & $\begin{array}{c}26.3 \\
18.8 \\
8.9\end{array}$ \\
\hline $\begin{array}{cl}\text { Europe } & \\
\bullet & \text { France } \\
\bullet & \text { Italy } \\
\bullet & \text { Turkey }\end{array}$ & $\begin{array}{l}10.0 \\
12.6 \\
11.2\end{array}$ & $\begin{array}{l}10.0 \\
11.5 \\
10.9\end{array}$ & $\begin{array}{c}9.8 \\
11.4 \\
11.2\end{array}$ & $\begin{array}{c}9.8 \\
11.1 \\
10.7\end{array}$ \\
\hline
\end{tabular}

Source: ILO, 2017

\section{Youth Unemployment}

Youth unemployment has also been a global challenge for several decades bedeviling several nations whether developed, developing or undeveloped. This global phenomenon became more pertinent since 2007 owing to the global economic crunch when youth unemployment increased by over 4 million, totaling about 75 million, thereby attaining a global rate of $13 \%$ (ILO, 2017a.). About $40 \%$ of the global jobless people are youth. The global youth unemployment rate was expected to rise in 2017, reaching 13.1 per cent, representing 70.9 million young unemployed. In the Arab States and Northern Africa youth unemployment rate was expected to reach the high point of 30.0 per cent in 2017 (ibid.). However, out of the whole, a distinction is usually made between the educated and the uneducated youth in the unemployment nexus and it is within this broader perspective that graduate unemployment should be understood. It remains difficult for young people to find jobs in most countries around the world. These trends persist despite considerable improvements in average educational attainment of the youth. The share of youth in the labour force with tertiary education has increased since 2007 in many countries, nonetheless, unemployment rates among young workers with tertiary education have also risen (ILO, 2017b.).

Youth employment features prominently in the Sustainable Development Goals. The 2030 Agenda for Sustainable Development for example, places full and productive employment and decent work for youth at the centre of the new development vision. It emphasizes the catalytic power of youth employment in poverty alleviation, economic growth, and peace and prosperity for all (United Nations, 2015). Targets under Goal 8 in particular, as well as several other goals, recognize the centrality of youth employment challenges, and open pathways for consistent and focalized action on decent jobs for youth, and youth development overall. Key youth-specific targets include, increasing the number of youth and adults who have relevant skills, including

${ }^{1} 2018$ figures - ILO projections. 
technical and vocational skills, for employment, decent jobs and entrepreneurship by 2030 and ensuring that all youth and a substantial proportion of adults, both men and women, achieve literacy and numeracy (ibid).

Generally, unemployment is highest among the educated youth as against the uneducated (UNECA, 2010). For instance, in 2003, the unemployment rate was $8.5 \%$ for the former and $6 \%$ for the latter groups in Ghana (Nsowah-Nuamah and Amankrah, 2003). This is because the educated have a tendency of picking among job opportunities using several variables but the uneducated are not (ibid.). This 'educated joblessness' is what has now become known as Graduate Unemployment; where people with university degrees cannot find suitable jobs commensurate with their final courses of choice. In response to the menace posed by the unemployed, the International Labour Organisation has updated its definition of unemployment as the numbers of the economically active population who are without work but available for and seeking work (ILO, 2013).

Wilson argues that "the twin impact of globalisation and technological modernisation necessitates the education and training of knowledge workers, who are able to use logical-abstract thinking to diagnose problems, research and apply knowledge, propose solutions, and design and implement those solutions, often as a team member"' (Wilson 2005, p. 84). He argues further that secondary education in Africa should focus its skills development agenda on what it can do well, i.e. develop a generic set of key competencies which are regarded as relevant to the demands of the labour market. According to David Wilson, "what has been crafted into the case of the key competencies is a discourse in which vocational education no longer means training in particular occupational categories, but aiming for a more abstracted, undifferentiated worker-citizen able to bring a set of generic competencies to any vocation."(ibid.).

\section{Youth Unemployment in Ghana}

The Youth in Ghana is defined as persons with ages between 18 -35 years (MOYS, 2010; GSS 2010). Ghana's youth constitute about $22.6 \%$ of the economically active population. Youth unemployment has been a major socio-economic challenge facing the country. Research has shown that about 300,000 young graduates enter the labour market every year with less than $6,000(3 \%)$ getting formal employment. It is also believed that only two out of ten graduates who complete national service every year get employment in the formal sector. The African Centre for Economic Transformation (ACET) has indicated that the greatest challenge facing Ghana is rising youth unemployment. A study conducted stated that about 48 percent of youth in Ghana are unemployed and warned that the persistent high youth unemployment in Ghana could pose serious security challenges to the country in the near future if it is not addressed effectively (ACET, 2016). Whilst these statistics may be very alarming, many young graduates still hold the notion that it is the responsibility of the state to provide for their economic needs and expect the government to employ them. As a result, unemployment still constitutes a major challenge. There is also enough evidence of widespread disparity between the calibre and skill sets in graduates that educational institutions produce and what the demand of the labour market requires. This trend has led to a 'mismatch' between educational output and labour market requirements creating unemployment in the country (Karikari-Ababio, 2016;Amankrah, 2016).

A number of factors account for the growing youth unemployment in Ghana. Historical evidence indicates that youth unemployment in Ghana is due to, on the one hand, a more than a threefold increase in the youthful population over the last forty years, and, on the other hand, failure of the economy to generate sufficient employment outlets (Amankrah, 2010). The Ministry of Manpower, Youth and Employment in a study identified a number of factors contributing to this phenomenon (MMYE, 2006). According to the study, the causes of youth unemployment in Ghana include the following:

- the introduction of the Junior Secondary School and Senior Secondary School system without adequate planning for integration into the trades/vocations and job placement;

- education and training have no link to the needs of the important sectors of the economy;

- the near collapse of Ghana's industrial base due to ineffective management of the divestiture process which resulted in the closure of many factories without a structural transformation of the economy to generate alternative jobs for people;

- the shrinking of public sector employment opportunities coupled with a relatively slow growth of the private sector; and

- the lack of a coherent national employment policy and comprehensive strategy to deal with the employment problem (ibid.).

In recognition of the above challenges, the government of Ghana in 2006 established the National Youth Employment Programme (NYEP) to stimulate entrepreneurial endeavour among the youth. In addition, there have been a number of interventions aimed at stimulating entrepreneurial endeavour. These have included the Rural Enterprises Programme (REP), Skills Development Fund SDF), Ghana Youth Employment and Entrepreneurial Development Agency (GYEEDA), Integrated Youth Community Centres (ICCES), Microfinance and Small Loans Centre (MASLOC), Local Enterprises and Skills Development Programme (LESDEP), Youth enterprise Support (YES) and Savannah Accelerated Development Programme (SADA). 
While all these efforts are very laudable, they have achieved limited success because of the way they were implemented. A lack of partnership with key training institutions, political colourisation and improper implementation mechanisms undermined success (World Bank, 2016; Honorati and de Silva, 2016).

\section{METHODOLOGY}

This study was conducted during a residential training session for national service personnel who were just about the end their one-year compulsory national service in one of the regions in Ghana. Many of them had not secured jobs as at the time of the training. Consent was sought from the course participants who were from various tertiary institutions (universities and polytechnics) across the country and had been posted to the study region for national service. Their views could therefore be assumed as representative of the general mass of the graduate student body. The research also sought information and other perspectives from the private sector and from government through a dual-pronged strategy of data collection at the level of employers' associations, complemented by some institutional level interviews.

The study combined quantitative and qualitative methodologies. A self-completion questionnaire to collect both qualitative and quantitative information was administered. Alongside qualitative differences, a questionnaire offers the opportunity to look for statistically significant trends and differences and enables responses to be gathered from large numbers relatively quickly, and cost efficiently (De Vaus 1991; Fink 1995). However, a questionnaire is likely to produce less in-depth responses, and prevent the researcher from probing responses further. As such, when discussing issues about individual perspectives and choices, preferences are likely to vary in relation to their context and belief systems. Consequently, a qualitative method of data collection would enable participants to express their views reflecting their individual experiences.

The first stage was the questionnaire survey to all the training participants. They were distributed to 100 participants on the third day of the training programme. There was a $100 \%$ rate of return. One could assume the issue of power relations between the researchers who were at the same time trainers of the participants. There was however no coercion to fill the questionnaire, hence responses were collected the next day. Participants were assured of anonymity and confidentiality. The survey provided the baseline description for the participant's purposes for their undergraduate studies, expectations and experiences on a range of personal, social and academic challenges that they had faced during their undergraduate studies. As with qualitative research in general, the question of generalizability can best be addressed through methodological rigour with which a study is designed in order to highlight lived experiences that may be invisible in the positivists approaches (Yin 1989).

Following the work of Staus and Corbin (1998) an interview-based approach was used to obtain information from participants. In this regard, leaders of the various groups that total 7 were interviewed. Semistructured interview protocols were used for conducting the interviews. The open-ended questions allowed for free expression of individual opinion, thereby providing a variety of responses from the participants. Three focus groups discussions (FGD) were also conducted. Selection was done randomly and was based on the conference registration information. The FGD was employed to consolidate themes and verify findings. The comparison and synthesis of findings of both analyses aimed to increase validity and reliability within the limitations of the study.

Eight (8) persons representing the public and private sector were also interviewed $-(2$ members of the Ghana Employers' Association'1, 3 senior executives of different banks, 2 from the private sector and the Chief Director of the Ministry of Manpower, Youth and Employment were interviewed. It is instructive to note that 3 banks were selected as a result of about $70 \%$ of the respondents expressing interest in working in a bank. It was therefore, necessary to find out skills/competencies required by banks and how consistent these were spread among them. The employers association was selected because of it being the mouthpiece and representation of employers (non government) and the ministry representing government, hence the choice.

Data Management and Analysis (Survey, S-S Interviews \& FGD)

The responses from the survey were manually transferred from the questionnaires into a spreadsheet by putting each question number as a column heading whilst one row was used for each person's answers. Each possible answer was then assigned a 'code'. Each respondent's questionnaire was examined in turn and coded. The data was then entered into a spreadsheet and re-checked for accuracy. Using the spreadsheet, and adding a filter to each question within the spreadsheet, the number of people who responded to each question was obtained. Key responses were put in a tabular form and graphed. (See Fig.1 below)

From our field notebooks and from memory data collected were transcribed. The handwritten notes were then keyed into a computer and printed. The transcripts were read through a number of times to obtain a general sense of the data and to reflect on its overall meaning. For example, what general ideas are the interviewees getting across, what are the tones of these ideas, what themes are running through them, what is the general impression of the overall depth, credibility and use of the information (Cresswell, 2003). Patterns were identified

\footnotetext{
${ }^{1}$ Ghana Employers Association (GEA) - A national Employers' Organisation whose membership comprises enterprises operating in all sectors of the economy to promote the interest of employers and to act as a forum for employers.
} 
and as advocated by Miles and Huberman (1994); these were engaged with the research questions and the purpose of the study.

\section{FINDINGS AND DISCUSSION}

Findings of the survey, interviews and focused group discussions are grouped in three: responses from students, employers association together with the private sector and government (Ministry of Manpower, Youth and Employment).

\section{Students:}

Key findings from students are as follows:

1) Less than $30 \%$ of students had any knowledge about entrepreneurship

2) Knowledge gap for needed skills sets for the job market. Nearly $90 \%$ of students were ignorant of skills required at the Job market. Many thought that should have informed their choice of subjects at the university. As such there was a disconnect between programmes run at the Universities and Polytechnics during undergraduate studies on one hand and demands of the labour market.

3) Lack of counseling in respect of programmes and career at secondary schools. Over 30\% of students indicated that career counseling was non-existent and that where there was counselling, teachers focused on behaviour and morality.

4) Nearly $90 \%$ of national service personnel were now thinking of what to do after Service. They were willing to accept any job opening or offer, since the option was not being employed after national service. Many had already collected postgraduate application forms to continue their education, just in case job opportunities didn't come their way.

Figure 1:

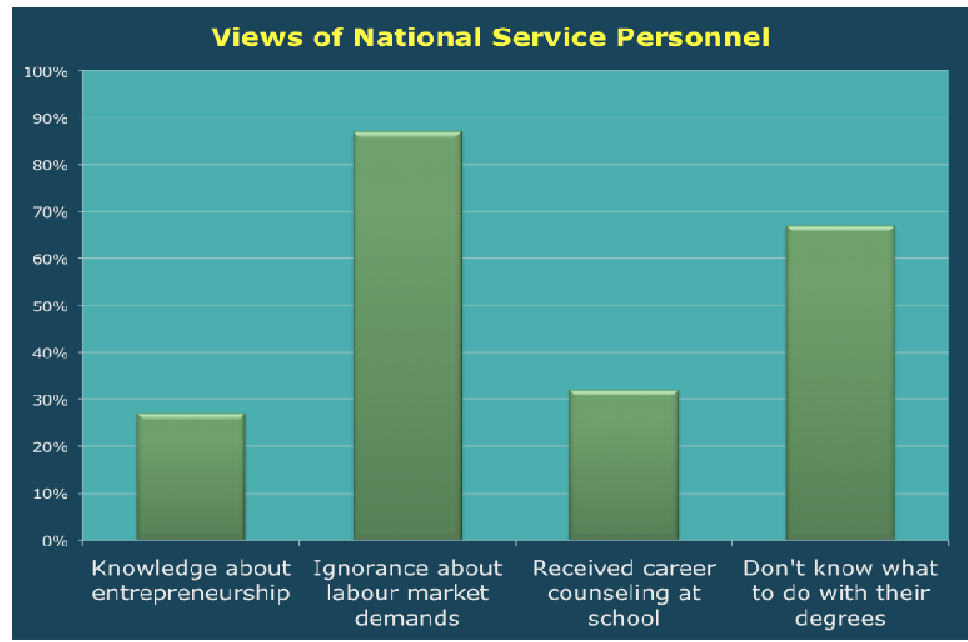

Below are excerpts from the interviews:

\section{Students:}

S1 "I didn't like the course I was offered at Legon, but my parents didn't have the money to send me to private university to do a course of my choice so I did it like that". (AF)

S2 "I was given a course I didn't choose and it could not be changed. I was told that what was necessary is to obtain a degree first and use that to determine what to do later". (JKBM)

S3 "I only heard about entrepreneurship when I finished the university". (JKA)

S4 "What is the use of just attending university if doesn't make you find work and become independent of your parents". (JOT)

S5 "I think I have wasted my four years as a graduate. I don't know what to do now. Since I can't find any Job I'll have to find a profession to pursue. Maybe, I'll read Law or do an MBA for now". (EPE)

These voices do not only portray the lack of support systems, including professional career counseling lacking in our educational system, but they also corroborate the reality of the incongruence between academia and industry in the areas of skills and required competencies. Clearly, those who feel frustrated take a line of action - more schooling, which means more costs to government and parents, but such a course only postpones the problem if a medium and long term solution is not found. As Lauglo points out: "for skills training to ease transition to work, a certain threshold of quality and level of skill is likely to be needed" (Lauglo 2005, p. 33). However, without classroom curricula and learning closely linked with what employers require and work experience, the skills acquired are bound to be superficial and unattractive to employers. It behoves on tertiary education providers, government and the private sector to play a major role in redeeming the missed opportunities at the pre-tertiary level and create the requisite environment to beef up the deficit and develop employable skills 
sufficient to enhance the transition between tertiary education and the world of work.

\section{Employers}

From the employers' perspective, responses were varied as indicated below. However, there was convergence in their expectations of skills and competencies required. They complained about lack of writing skills, communication skills, confidence, initiative, leadership, research skills, knowledge in basic office practice, selling skills and experience in minutes writing.

An advert for trainee managers attracted over 700 applicants, but we needed only 7. Results of the aptitude test conducted was shocking as basic English grammar, spelling and reasoning were major challenges they encountered. At the interview most of the students lacked confidence and interviewing skills. How can such people be salesmen? We'll have to spend money and train them to be fit for purpose. (NGL)

These days many people obtain first classes, but sometimes we wonder how they got that class. They don't know anything. We've had many regrets employing many of them. After spending 4 years at the university we expected to have people who are ready for work. (AGI)

... the energy situation too has not helped. Majority of our members cannot do more than 25\% of their regular production. They have therefore laid off many of their staff. Obviously, they can employ more people when they have scaled down operations. In addition to that, the interest rates are too high and this serves as a disincentive to expand even if the energy crises is solved. (AGI)

Some students from 2 particular universities are very good. There are two reasons basically. They have a very structured vacation training programme from levels 200 to 400 and they expose their students to project work and group assignments. In every three years they involve us in their curriculum review. With such collaboration, we do not only create spaces for students' vacation training, but we also take a minimum of 20 of their students for national service. (BBGL)

The issue of employability of graduates from our tertiary institutions has been of much concern. As an association for employers training programmes for certain competences are planned throughout the year but few of our membership participate. Our training and development department liaises with member companies and obtain feedback for critical training need areas. (GEA)

Government (Represented by the Chief Director of the Ministry of Manpower Development and Labour Relations):

A number of measures have been introduced to enhance the employability of the youth. First, in order to send the message on the crucial role of employment generation, the Ministry of Employment and Social Welfare was restructured and renamed as Ministry of Manpower Development and Empowerment in 2001 and later modified as Ministry of Manpower, Youth and Employment. The restructuring aimed at refocusing policies and programmes to support youth employment. Notwithstanding these efforts, youth unemployment continues to be a concern because of the increasing gap between labour supply and the opportunities for wage employment at the firm level. Equally disturbing is the increasing phenomena of young persons who live, sleep and work on the streets, thus deepening the incidence of poverty. (MMYE)

While the role of entrepreneurship is recognized, tertiary education institutions and other training institutions should strengthen structures and other processes to facilitate entrepreneurial education and training. In the same vein, policymakers and industry ought to turn their attention towards building entrepreneurship ecosystems and recognize the need for multifaceted support for entrepreneurial activity, as well as interactive effects within communities that accelerate efforts of individual entrepreneurs. Entrepreneurship is an important part of industrial growth and the backbone of any country for its economic development. The spirit of entrepreneurship brings about enthusiasm, persistence and the ability to seek entrepreneurial opportunities that lead to success. A country's ability to generate a steady stream of business opportunities can only come about when its people take to entrepreneurial activities. Entrepreneurs are thus, essentially the engines of growth for a country. However, the mismatch between academia and industry ought to be addressed. Rationalizing the curricula to reflect what the job market requires is necessary, but more important also, is how skills are transferred in an academic environment setting.

There are serious deficits of business experience in many of tertiary institutions. Whilst it not my intention to down-play the importance of academic instruction, clearly, it will require experienced business people to teach real-world business and entrepreneurial skills in the classroom and thus, creating opportunities to interact, challenge points of views and discuss business situations on an academic platform. Strong collaboration with industry will provide a good learning experience where practitioners are invited regularly to enhance the classroom experience Thus, teaching will be application oriented, with the objective of developing skills for the business environment and creating entrepreneurial managers for Corporate as well as for individual businesses. Entrepreneurship education could then enhance the building of confidence, motivate progress, strengthen the entrepreneurial mindset, foster a desire to achieve and inspire action.

Employment in the $21^{\text {st }}$ century is not a mater of getting a job. Forty years ago a young person graduating from a University could get a job and keep it for 30 years. Today, the business world has changed. Companies 
are downsizing, outsourcing, cutting expenses, operating on less staff and feeling less obligated to employees. Workers today have to be able to change with the times, adapt, learn new jobs and find ways to work tasks that have not even been invented yet. As a country we need people who are trained to be thinkers and learners and not just employees. Entrepreneurship education and training should therefore guarantee creative thinking, problem solving and leadership that will prepare young people particularly, for the work environment.

The narrative above seems to weigh heavily on the acquisition of the right skills and the role academia and industry ought to play to minimize the incongruence between knowledge and skill acquisition and practice. The critical role the business environment plays in shaping issues raised above cannot be overemphasized. Unfortunately, in many developing economies including Ghana, obstacles in the business environment close off entrepreneurial opportunities to huge swathes of the population. These barriers add to the usual challenges that entrepreneurs face with regard to capacity, financing, and market access as well. Thus, most would-be entrepreneurs face restricted options because they lack the connections, status, and resources enjoyed by established businesses and elite families. Women, youth, and non-elite individuals face higher hurdles to growing a business.

\section{CONCLUSION}

The vast majority of the working people in Ghana and the developing world are self-employed or work in small organizations. However, their income levels are not sufficient to lift them above grinding poverty and hit the desired targets. While economic and political reforms play an important role in setting the scene, people need knowledge, skills and mindset to take advantage of opportunities. Tertiary and training institutions should be supported to make the difference that is required. In the same vein,

Ghana faces a number of challenges that can only be met if it has innovative, well-educated, and entrepreneurial citizens who, whatever their walk of life, have the spirit and inquisitiveness to think in new ways, and the courage to meet and adapt to the challenges facing them. Moreover, a dynamic economy, which is innovative and able to create the jobs that are needed, will require a greater number of young people who are willing and able to become entrepreneurs; young people who will launch and successfully develop their own commercial or social ventures, or who will become innovators in the wider organisations in which they work. Because education is key to shaping young people's attitudes, skills and culture, it is vital that entrepreneurship education is addressed from an early age. Entrepreneurship education is essential not only to shape the mindsets of young people but also to provide the skills and knowledge that are central to developing an entrepreneurial culture.

If indeed entrepreneurship creates jobs, drives economic growth, and fosters innovation, then country states, particularly Ghana should be given it much more attention than it has been given now. Its significance continues to be touted by governments, academia and the private sector; yet, little has been done to actualize its momentous role. A key reason in my view is that the inherited colonial educational system which focused on the development of clerical and literacy skills deemed necessary for colonial administration and for making good employees, rather than entrepreneurs out of locals has not gone through the needed transformation required, despite the many educational reforms. That legacy continues and although most universities in Ghana have begun to offer entrepreneurship courses in recent years, entrepreneurship is taught like any other course. The transformation that is required is urgent.

\section{References}

Acs Z. and Armington, C. (2004) "Employment Growth and Entrepreneurial Activity in Cities." Regional Studies 38, no. 8, 911-927.

Adams, A. (2007). The role of youth skills development in the transition to work: A global review. Washington, DC: World Bank.

AEO (African Economic Outlook). (2014). Youth in African labour markets. Too many bad jobs in poor countries, too few jobs in middle income countries from http://www.africaneconomicoutlook.org/en/indepth/youth_employment/youth-in-african-labour-markets/.Accessed 26 January 2018

African Centre for Economic Transformation ACET, (2016). Accessed January 27, 2018 from http://acetforafrica.org/highlights/youth-unemployment-ghanas-major-challenge-acet/

africaneconomicoutlook.org/en/in-depth/youth_employment/youth-in-african-labour-markets/.

Akyeampong, A. (2014). Reconceptualised life skills in secondary education in the African context: lessons learnt from reforms in Ghana. International Review of Education, 60 (2). pp. 217-234.

Amankrah, J. (2016). Youth Unemployment in Ghana: Prospects and Challenges. Accra, Centre for Economic Policy Analysis.

Amankrah, J. \& Burggraaff, E. (2012). Learn4Work Mapping Study Ghana: Needs and priorities in countries, too few jobs in middle income countries. Accessed 26 February 2014 from http://www.

Creswell, J. (2003). Research Design: Qualitative, Quantitative and Mixed Methods, 3rd Edition. London \& 
New Delhi: SAGE Publications.

De Vaus, D. (1991) Surveys in Social Research, 3rd Edition (London: Routledge). demand-driven vocational training of youth. Amersfoort: Edukans Learn4Work.

Fink, A. (1995). The Survey Handbook (SAGE: London).

Ghana Statistical Service (2007). Report on 2006 Job Tracking Survey. Accra: GSS.

Gird, A., \& Bagraim, J.J., (2008),’The theory of planned behaviour as predictor Of entrepreneurial intent amongst final-year University students", Journal of Psychology, Psychological Society of South Africa. All rights reserved. South African, 38(4), pp. 711-724 ISSN 0081-2463

Honorati, M. and de Silva, S. (2016). Expanding Job Opportunities in Ghana. Directions in Development. Washington, DC: World Bank.

ILO, (2017). Global Employment Trends for Youth 2017 | Paths to a better working future

International Labour Office (ILO). 2013. Statistics of Employment, Unemployment, Underemployment: Economically Active Population. (Geneva).

International Labour Office (ILO). 2016 Global Wage Report 2016/17: Wage inequality in the workplace (Geneva).

International Labour Office (ILO). 2017a. World Employment and Social Outlook (WESO): Trends 2017 (Geneva).

International Labour Office (ILO). 2017b. Global Employment Trends for Youth (GETY) 2017: Paths to a better working future (Geneva).

Jaafar, M. and Abdul Aziz, A. (2008),'Entrepreneurship Education in Developing Country Exploration on Its Necessity in the Construction Programme", Journal of Engineering, Design and Technology, Vol. 6 No. 2 , 2008, pp. 178-189, Emerald Group Publishing Limited.

Karikari-Ababio, M. (2016). Dynamics of persistent underdevelopment: The case of Ghana. Accra: Smartline Ltd.

Lauglo, J., \& Maclean, R. (Eds.). (2005). Vocatioanalisation of secondary education revisited. UNEVOC Technical and vocational education and training series. Dordrecht: Springer.

Miles, M. and Huberman, M. A. (1994). Qualitative Data Analysis, $2^{\text {nd }}$ Edition. Beverly Hills: SAGE Publications.

Ministry of Manpower, Youth and Employment (MMYE, 2006). Ghana Youth: Working to Build our Future Accra: MMYE.

Ministry of Manpower, Youth and Employment (MMYE, 2006). Ghana Youth: Working to Build our Future. Accra, MMYE.

Ministry of Youth and Sports (2010). National Youth Policy of Ghana. Accra. MOYS.

MoE (Ministry of Education). (2010). Education sector performance report, Accra: MoE.

Nabi,G., \& Linan,F.,(2011),"Graduate entrepreneurship in the developing world: intentions, education and development", Education + training, Vol. $53: 5$, pp.325-334

Nsowah-Nuamah, .N. and Amankrah J. (2003) Report on Registration of Unemployed and Underemployed Persons, Ministry of Manpower Development and Employment, Ghana on the Ghana Job Tracking Survey. Accra: GSS.

Strauss A. and Corbin J. (1998). Basics of qualitative research: grounded theory procedures and techniques. Thousand Oaks (CA): Sage Publications.

Teixeira, A,., \& Forte, R., (2009). "Unbounding entrepreneurial intents of university students: a multidisciplinary perspective", FEP working papers, n. 322 April 2009, Faculdade De Economia, Universidade Do Porto.

United Nations (2015). Transforming our world: The 2030 Agenda for Sustainable Development, General Assembly, 70th session, Resolution adopted by the General Assembly on 25 Sept. 2015, A/RES/70/1 (New York).

United Nations Economic Commission for Africa. (2010). Unemployment, Underemployment and Vulnerable Employment in West Africa: Critical Assessment and Strategic Orientations. Retrieved from http://www.uneca.org/wa/documents/RapportEco2010- Partie2ENG.pdf on 26/01/2018 Washington, DC: The World Bank.

Wilson, D. (2005). Promise and performance in vocationalised secondary education: Has the baby been thrown out with the bath water? pp. 71-90.

World Bank (2005). Expanding opportunities and building competencies for young people: A new agenda.

Yin, R. (2003). Case Study Research: Design and Methods, ( ${ }^{\text {rd }}$ Edition). Sage Publications. 